Arch. Dis. Childh., 1966, 41, 309.

\title{
Obesity in Childhood
}

\section{A Controlled Trial of Anorectic Drugs}

\author{
JOHN LORBER \\ From the Department of Child Health, University of Sheffield
}

Obesity in childhood is a common problem. Its management by diet, and by advice about exercise is notoriously difficult, and the long-term prospect, even in those who achieve good initial weight reduction, is also unfavourable. Some four-fifths of obese children become even more obese adults, even in the best hands (Wolff, 1962). Although the use of appetite-reducing agents is generally not favoured, and though their indiscriminate use should be condemned, it was felt that under carefully controlled conditions their place should be evaluated by controlled trials. During 1959-60 we carried out such a trial, the first in a series (Lorber and Rendle-Short, 1961) in which we compared the effects of (a) phenmetrazine, a long-acting amphetamine resinate, $7 \cdot 5 \mathrm{mg}$. daily, (b) a low-calorie low carbohydrate diet, and (c) a dummy tablet. The controlled trial lasted for 3 months. The effectiveness of the three different régimes was of the same order. The maximum weight reduction occurred in the first month of treatment, irrespective of the régime. There were no side-effects from the drugs used. It was, therefore, decided to use a higher dose of amphetamine resinate in this next trial and to study a new drug, phentermine (phenyl-tertiarybutylamine, bonded to sulphonic acid resins). It was claimed that tolerance to this drug by the appetite-suppressing mechanism developed more slowly than in the other commonly used anorectic agents (Cass, 1959; LeRiche, 1960). Phenmetrazine was not used in this second trial, which in every other respect was planned as our first trial.

\section{Planning the Trial}

The children and their parents were told that we were trying the effect of three different types of capsules (amphetamine resinate, phentermine, and a placebo) and that with one set of capsules there would be a diet. When given the inert capsule, containing $300 \mathrm{mg}$.

Received September 24, 1965. lactose, the patients were also given a diet sheet. This stated:

'Your child may eat or drink anything except: snacks between meals, any sweets or chocolates, any sweetened drinks or ice cream. Not more than three slices of bread each day. No cakes, pastries, or biscuits. Not more than four small potatoes a day. No peas or beans. No jam, marmalade, or honey. No tinned fruits. (As much fresh vegetables and fruit as you like.) This diet is to be used only with the present lot of tablets.'

The children were given sufficient tablets or capsules for 28 days. The second régime was then automatically prescribed, and the third régime began at the end of the second 28-day period. The mother was also asked to report at each visit any of the following side-effects: drowsiness, sleeplessness, temper tantrums, irritability, unsteady gait, increased appetite, poor appetite, lack of interest, or increased interest. The order in which the children received the three forms of treatment was determined by random sampling, and neither the doctor nor the patient knew which drug the child was receiving.

The daily dose of the amphetamine resinate was $12 \cdot 5$ mg. and of phentermine $15 \mathrm{mg}$., taken as one capsule before breakfast. The first phase of the trial was concluded after 12 weeks. Treatment was then continued with the régime which had proved most successful during the preceding 12 weeks. If the diet was nearly as effective as the drug treatment, then dietary treatment was again given, with placebo capsules. Later, when a régime lost its effectiveness and the children still required treatment, then treatment was changed to one of the other previously used régimes. In case all three régimes failed at any time, phenmetrazine was given in a dose of $25 \mathrm{mg}$. twice daily. If weight reduction was no longer desired, then no capsules were given, but the children were asked to conform to the instructions of the diet sheet. If they relapsed (as they usually did), a further course of amphetamine resinate or phentermine was prescribed.

None of the children were admitted to hospital for treatment of their obesity.

In this paper it is proposed to present the results obtained during the first 12 weeks, i.e. the controlled part of the trial in detail; but the results obtained after this period can only be presented in broad outline, 
because many children did not attend regularly or defaulted after variable periods of observation and treatment. Further, the great variability of the sequence of the régimes used does not render this later part of the study readily analysable, except in general terms.

TABLE I

Obesity Trial, May 1961-May 1963*

\begin{tabular}{ll|c|c|c|c}
\hline & & $3-10$ years & $11-12$ years & $13-15$ years & All ages \\
\hline Girls &. & 14 & 17 & 11 & 42 \\
Boys.. &. & 6 & 13 & 7 & 26 \\
\hline Total &. & 20 & 30 & 18 & 68 \\
\hline
\end{tabular}

^ Number enrolled in the trial: 84. Number who completed 3 months of treatment: 68 .

TABLE II

Initial Excess of Weight related to Height (according to Tanner, 1958)

\begin{tabular}{c|c|c}
\hline $\begin{array}{c}\text { Percentage } \\
\text { Excess Weight }\end{array}$ & No. & $\%$ \\
\hline $20-32$ & 8 & 12 \\
$33-49$ & 19 & 28 \\
$50-74$ & 8 & 41 \\
$75-99$ & 5 & 12 \\
100 or more & 7 \\
\hline
\end{tabular}

TABLE III

Initial Height

(according to Tanner, 1958)

\begin{tabular}{|c|c|c|c|c|c|c|}
\hline \multicolumn{5}{|c|}{ Percentile } & \multicolumn{2}{|l|}{ No. } \\
\hline $\begin{array}{cc}<25 & \ldots \\
25-49 & \ldots \\
50-74 & \ldots \\
75-89 & . \\
90-97 & . \\
90 \text { and over }\end{array}$ & $\begin{array}{l}\cdots \\
\cdots \\
\cdots \\
\cdots \\
\cdots\end{array}$ & $\begin{array}{l}\ldots \\
\cdots \\
\cdots \\
\cdots\end{array}$ & $\begin{array}{l}\ldots \\
\cdots \\
\cdots \\
\cdots \\
\cdots\end{array}$ & \begin{tabular}{l|}
$\cdots$ \\
$\cdots$ \\
$\cdots$ \\
$\cdots$
\end{tabular} & $\left.\begin{array}{r}2 \\
8 \\
15 \\
21 \\
17 \\
5\end{array}\right\}$ & $43(63 \%)$ \\
\hline
\end{tabular}

\section{Case Material}

Between May 1961 and May 1963, 84 children suffering from simple nutritional obesity were admitted to the trial, but as only 68 completed the 12 -week course, only these 68 will be analysed. Of the other 16, one developed side-effects from phentermine and had to be excluded from the trial and the other 15 failed to keep their appointments.

There were 42 girls and 26 boys, between the ages of 3 and 15 (Table I). The youngest child was 3 years 9 months of age and by then weighed $31 \frac{1}{2} \mathrm{~kg}$., which was nearly double his expected weight. All children were grossly obese, weighing at least $20 \%$ more than their expected weight for their age and height, and 5 children weighed more than twice their expected weight (Table II). The heaviest child weighed $100.5 \mathrm{~kg}$. at the age of 13 years and 9 months.
The large majority of the children were also above average height, and $43(63 \%)$ were at the 75 th percentile or taller on admission (Table III). Two children were below the 25 th percentile, but one of these was 15 years old and had already attained her full height. It is well known that obese children are on the whole taller than average until puberty, but that growth ceases sooner and they do not, as a group, grow into tall adults. This feature was well shown in this group, in which at the end of the period of observation only $40 \%$ were at the 75 th percentile or above in height, and the height curve of most others indicated that they would not be above average when fully grown.

\section{Results}

As in our first trial (Lorber and Rendle-Short, 1961), the whole group did much better in the first month of treatment than at any other similar period subsequently. 66 of the 68 lost weight. The average loss for all the 68 children was $2 \cdot 6 \mathrm{~kg}$. In the second month 57 of the 68 lost weight and the average loss of the whole group was $1 \cdot 2 \mathrm{~kg}$. In the third month only 48 of the 68 lost weight and the average loss fell to $0.9 \mathrm{~kg}$. for the whole group. The total average loss for the first three months of the trial was $4 \cdot 7 \mathrm{~kg}$. (Table IV).

An approximately equal number of children received amphetamine resinate, phentermine, or diet (with placebo) during each 4 -week period. In the first month those who received amphetamine resinate did best, by losing an average of $3.4 \mathrm{~kg}$. as compared with $2 \cdot 2 \mathrm{~kg}$. and $2 \cdot 1 \mathrm{~kg}$. by those who received phentermine or diet first, respectively. In the second and third months the effectiveness of all régimes declined, and the difference between amphetamine resinate and phentermine disappeared. During the second and third months patients on these drugs lost an average of $1.5 \mathrm{~kg}$. The effectiveness of the diet diminished most. In the second month those on diet lost an average of only $0.5 \mathrm{~kg}$. and there was no loss at all in the third month. In the second month only 13 out of 20 and in the third only 12 out of 26 lost weight. One child gained $2 \cdot 1 \mathrm{~kg}$. while he was supposed to be on a low calorie diet (Table IV).

Gains in weight were noted in 7 out of 68 on dextroamphetamine, 4 on phentermine, and 22 on placebo capsules. One child lost $8.5 \mathrm{~kg}$. in the first month of treatment on dextroamphetamine.

The effectiveness of the diet in this trial was very similar to that in our first trial (Lorber and RendleShort, 1961), but the increased dose of amphetamine resinate $(12.5 \mathrm{mg}$.) led to considerably increased weight loss as compared with that obtained with the earlier dose (7.5 mg.). Phentermine was somewhat more efficient than either diet or the lower dose of 
TABLE IV

Results in First Three Months of Treatment (double-blind controlled trial)

\begin{tabular}{|c|c|c|c|c|c|c|c|c|c|}
\hline \multirow{2}{*}{ Period } & & \multicolumn{2}{|c|}{$\begin{array}{l}\text { On Long-acting } \\
\text { D-amphetamine }\end{array}$} & \multicolumn{2}{|c|}{ On Phentermine } & \multicolumn{2}{|c|}{ On Placebo } & \multicolumn{2}{|c|}{ Any Régime } \\
\hline & & $\underset{\text { Weight }}{\text { No. Losing }}$ & $\begin{array}{c}\text { Average } \\
\text { Loss (kg.) }\end{array}$ & $\begin{array}{c}\text { No. Losing } \\
\text { Weight }\end{array}$ & $\begin{array}{c}\text { Average } \\
\text { Loss (kg.) }\end{array}$ & $\underset{\text { Weight }}{\text { No. Losing }}$ & $\begin{array}{c}\text { Average } \\
\text { Loss (kg.) }\end{array}$ & $\underset{\text { Weight }}{\text { No. Losing }}$ & $\begin{array}{c}\text { Average } \\
\text { Loss (kg.) }\end{array}$ \\
\hline $\begin{array}{l}\text { First month } \\
\text { Second month.. } \\
\text { Third month . }\end{array}$ & $\begin{array}{l}\ldots \\
\cdots\end{array}$ & $\begin{array}{l}22 / 22 \\
21 / 24 \\
18 / 22\end{array}$ & $\begin{array}{l}3 \cdot 4 \\
1 \cdot 3 \\
1 \cdot 7\end{array}$ & $\begin{array}{l}23 / 24 \\
23 / 24 \\
18 / 20\end{array}$ & $\begin{array}{l}2 \cdot 2 \\
1 \cdot 6 \\
1 \cdot 4\end{array}$ & $\begin{array}{l}21 / 22 \\
13 / 20 \\
12 / 26\end{array}$ & $\begin{array}{l}2 \cdot 1 \\
0.5 \\
0.0\end{array}$ & $\begin{array}{l}66 / 68 \\
57 / 68 \\
48 / 68\end{array}$ & $\begin{array}{l}2 \cdot 6 \\
1 \cdot 2 \\
0 \cdot 9\end{array}$ \\
\hline
\end{tabular}

TABLE V

Combined Results of Trials 1 and 2 showing Weight Loss and Number of Children Losing Weight during One Month's Treatment on Different Régimes

\begin{tabular}{|c|c|c|c|c|c|c|c|}
\hline & & \multirow{2}{*}{ Diet (1) } & \multirow{2}{*}{ Diet (2) } & \multirow{2}{*}{$\begin{array}{c}\text { Phenmetrazine } \\
\text { (1) }\end{array}$} & \multicolumn{2}{|c|}{ Amphetamine Resinate } & \multirow{2}{*}{$\begin{array}{l}\text { Phentermine } \\
\text { (2) }\end{array}$} \\
\hline & & & & & $7.5 \mathrm{mg} .(1)$ & $12.5 \mathrm{mg} .(2)$ & \\
\hline $\begin{array}{l}\text { No. losing weight } \\
\text { Average loss (kg.) }\end{array}$ & 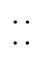 & $\begin{array}{c}48 / 61 \\
1 \cdot 0\end{array}$ & $\begin{array}{c}46 / 68 \\
0.8\end{array}$ & $\begin{array}{c}52 / 61 \\
1 \cdot 0\end{array}$ & $\begin{array}{c}51 / 61 \\
1 \cdot 0\end{array}$ & $\begin{array}{c}61 / 68 \\
1 \cdot 9\end{array}$ & $\begin{array}{c}64 / 68 \\
1 \cdot 3\end{array}$ \\
\hline
\end{tabular}

(1) Trial 1 (Lorber and Rendle-Short, 1961) compared the effects of diet, of phenmetrazine, and of amphetamine resinate in small doses (7.5 mg.)

(2) Trial 2 refers to the present trial, comparing diet, amphetamine resinate in higher dosage (12.5 mg.), and phenmetrazine.

amphetamine resinate or phenmetrazine in the dose used. Table $\mathrm{V}$ shows the combined results of our two trials.

Follow-up. After the end of the fully controlled trial the trend in those 53 children who completed the fourth month of treatment showed little difference in the effectiveness of the two drugs used (42 children), but there was a continuation in the trend towards failure in those 11 who were on diet again. These 11 all did well when they were on diet for the first time, but on the second occasion 7 of them gained weight and now the whole group gained an average of $0.2 \mathrm{~kg}$. One child gained $3 \mathrm{~kg}$. in four weeks. This kind of experience was repeated again and again, when many children, now approaching normal weight, were put on to diet again.

Altogether 11 children achieved a normal weight within six months of treatment, but then under longer observation, and in spite of all efforts to maintain their courage and determination, most of them relapsed. It is impossible to give an exact assessment of the progress of the whole group, as so many failed to attend after variable periods. In several of these, however, it was possible to obtain their weight and height from their school records. There were altogether 53 children who have been so followed for between 12 months and $3 \frac{1}{2}$ years (Table VI). At the last examination only 2 were of normal weight; 5 were much improved, but still moderately obese (excess weight $6-13 \frac{1}{2} \mathrm{~kg}$.); 23 were improved but still very obese (up to $26 \mathrm{~kg}$. excess weight); 13 were not improved (up to $37 \mathrm{~kg}$. excess weight); and 10 were worse than on enrolment, with excess weights of up to $40 \mathrm{~kg}$.

This assessment is no doubt over-optimistic, as it is not known what happened to those who ceased to attend the clinic beyond a certain time. Up to April 1965, 57 children could have been observed for 3 complete years but only 13 were still attending.

Side-effects. There were very few side-effects from the drugs used. Irritability was occasionally mentioned, mostly by those who were on placebo capsules (? hunger). Only one child had insomnia while taking phentermine, but this was so severe that the drug had to be abandoned and she was taken out of the trial. The same child had no insomnia on amphetamine resinate.

No child taking drugs was restless or excitable, and these side-effects, which are common when amphetamine is taken, did not occur with the slowly

\section{TABLE VI}

Assessment at Last Examination in Those Followed for 1 Year or Longer

\begin{tabular}{|c|c|c|c|c|c|c|}
\hline \multicolumn{6}{|c|}{ Results } & \multirow{2}{*}{$\begin{array}{r}\text { No. } \\
2 \\
5 \\
23 \\
13 \\
10\end{array}$} \\
\hline $\begin{array}{l}\text { Became normal } \\
\text { Much improved, } \\
\text { Improved, but stil } \\
\text { No improvement } \\
\text { Worse }\end{array}$ & $\begin{array}{c}\text { at sti } \\
\text { very } \\
\ldots \\
\ldots\end{array}$ & $\begin{array}{c}\text { nod } \\
\text { pese } \\
\ldots \\
\ldots\end{array}$ & $\begin{array}{l}\ddot{e l y} \\
\cdots \\
\cdots \\
\cdots\end{array}$ & $\begin{array}{l}\ddot{\text { ese }} \\
\ldots \\
\ldots \\
\cdots\end{array}$ & $\begin{array}{l}\cdots \\
\cdots \\
\cdots \\
\cdots\end{array}$ & \\
\hline Total .. & $\ldots$ & .. & . & $\cdots$ & $\ldots$ & 53 \\
\hline
\end{tabular}


sustained release preparation used in this trial. There was no suggestion of habit formation and none became addicts to either drug. There were no withdrawal symptoms on stopping treatment, other than overeating and excessive gain of weight.

\section{Discussion}

We do not in general advocate drug treatment by anorectic agents of overweight children. There are, however, many children, who are so grossly overweight and under such poor parental control, that to expect sustained good results from advice and dietary treatment alone is unrealistic. In fact, most of the patients in this series had undergone some kind of dietary treatment before they were referred and were included in this trial. The experience with dietary treatment in this trial also showed how very ineffective dietary advice was, after the initial enthusiasm had worn off. It must be remembered, however, that these were highly selected extremely obese children, specially picked by the school medical officers for referral, because of the extreme degree of their obesity and of their failure to respond to simple measures. It is not that the diet was ineffective but that it was not adhered to.

Looking at the results in this context, those achieved by amphetamine resinate and to a slightly lesser extent by phentermine were satisfactory on a short- to medium-term basis. Unfortunately, after several months of treatment their effect tended to wear off and the patients often forgot to take them or did not attend for fresh prescriptions at the right time. This is the usual outcome whatever anorectic drugs are used (Seaton and Duncan, 1965).

To achieve successful long-term results in these cases one needs to treat not only the child but the whole family. Without it, and without the full enthusiastic support and interest of the patient, even spectacular initial successes will be followed by relapse and failure.

\section{Summary}

In a controlled therapeutic trial, 68 obese children were treated successively with (1) amphetamine resinate, (2) phentermine, and (3) diet with placebo capsules. Considerable weight reduction was achieved by all three régimes initially, but the effectiveness of all three tended to wane, especially that of diet. Long-acting amphetamine resinate was the most successful drug. Side-effects were very rare. The long-term prognosis of severe obesity in children still remains unsatisfactory.

I am very pleased to acknowledge the help from Dr. E. G. M. Oates, Principal School Medical Officer of the City of Sheffield, who referred most of the children for treatment. The amphetamine resinate (Durophet). the phentermine (Duromine), and the placebo capsules were generously supplied by Riker Laboratories.

\section{REFERENCES}

Cass, L. J. (1959). Evaluation of appetite suppressants. Ann. intern. Med., 51, 1295.

LeRiche, H. (1960). A study of appetite suppressants in a general practice. Canad. med. Ass. F., 82, 467.

Lorber, J., and Rendle-Short, J. (1961). Obesity in childhood: a controlled trial of phenmetrazine, amphetamine resinate, and diet. Quart. Rev. Pediat., 16, 93.

Seaton, D. A., and Duncan, L. J. P. (1965). The uses and abuses of appetite suppressants. Brit. F. clin. Pract., 19, 89.

Tanner, J. M. (1958). The evaluation of physical growth and development. In Modern Trends in Paediatrics (Second Series), ed. A. Holzel and J. P. M. Tizard, p. 325. Butterworth, London.

Wolff, O. H. (1962). Obesity in childhood and its effects. Postgrad. med.F., 38, 629 . 